\title{
TCR Recognition and Selection In Vivo
}

\author{
M.M. Davis, ${ }^{*} \dagger$ L.J. Berg, $\uparrow$. A.Y. LIN ${ }^{*} \dagger$ B. Fazekas De St. Groth, $\dagger$ \\ B. Devaux, ${ }^{*} \dagger$ C.G. Sagerstrom, $\dagger$ P.J. BJorkman, $\dagger \ddagger$ and J.F. ElliotT $\dagger$ \\ *Howard Hughes Medical Institute and $\dagger$ The Department of Microbiology and Immunology, \\ Stanford University School of Medicine, Stanford, California 94305-5428; $\ddagger$ Biology Division, \\ The California Institute of Technology, Pasadena, California 95205; \$The DNAX Research Institute of \\ Molecular and Cellular Biology, Palo Alto, California 95304
}

Much has been accomplished in identifying the molecules and genes responsible for T-cell recognition. We are now familiar with two distinct heterodimers, $\alpha \beta$ and $\gamma \delta$, and we know that the former (at least) confers on a $\mathrm{T}$ cell the ability to recognize antigens complexed with specific molecules of the major histocompatibility complex (MHC) (Dembic et al. 1986; Saito and Germain 1987). Because of the recent solution of an MHC class I structure (Bjorkman et al. 1987a,b), its apparent generalization to class II molecules (Brown et al. 1988), as well as the similarity of T-cell receptor (TCR) primary sequences to immunoglobulins (Igs), we can guess a great deal about how they might interact (Chothia et al. 1988, Claverie et al. 1989; Davis and Bjorkman 1988; see also Bjorkman and Davis, this volume). These remain speculations, however, until we can derive real biochemical and structural data from the event itself (e.g., TCR-antigen-MHC interaction). This is required in order to move the current state of affairs beyond the inferences that we are limited to by the indirect nature of current assay methods. Toward such a biochemical resolution of this issue, we have for some years been attempting to express TCR heterodimers in a soluble form, first as immunologic chimerics, with limited success (Gascoigne et al. 1987), and more recently as lipid-linked molecules that can be cleaved off the surface of expressing cells (A. Lin et al.; B. Devaux et al.; both in prep.).

In contrast with the situation in the periphery, where the ligand for TCRs antigen-major histocompatibility complex (Ag-MHC) seems clear, what happens in the thymus with regard to T-cell repertoire selection is not so well understood. In investigating this area, we have made transgenic mice carrying TCRs of defined specificity (Berg et al. 1988, 1989a,b; Ivars et al. 1988; B. Fazekas de St. Groth et al., in prep.). In addition, MHC transgenics provided through a collaboration with C. Benoist and D. Mathis (van Ewjik et al. 1988) have provided an invaluable tool in characterizing some of the TCR/MHC interactions that must occur in the thymus. This has provided useful insights into both positive and negative selection, as discussed below. Although we do not yet know the precise molecules that may be involved, ultimately the combination of soluble TCRs and TCR transgenic mice should provide a solid basis for exploring these phenomena. One scenario would be that since a particular MHC molecule is all that is required for T-cell export from the thymus (in the absence of nominal antigen) then a TCR/MHC interaction alone (or with a neutral peptide in the structure) may be possible. This should be detectable with a soluble receptor, and the relative affinity of such an event could serve as predictor of the fate of a given TCR in the thymus.

\section{Soluble TCR Heterodimers}

Because TCR heterodimers are assembled with the CD3 polypeptides to form complexes of at least seven polypeptides before appearing in the surface (Minami et al. 1987), they may be one of the more difficult types of molecules to produce in a soluble form. On the other hand, the very immunoglobulin-like character of its variable (V), diversity (D), joining (J), and constant (C) region elements, makes it very likely that it can bind to Ag-MHC by itself and that structurally it could exist and bind to its ligand in solution much like an antibody. Thus, the challenge has been to find conditions in which TCR chains can be expressed and form heterodimers free of $\mathrm{CD} 3$ molecules, either secreted from cells in culture or in a membrane-associated form that could be easily cleaved from the surface. Initial attempts in our laboratory took the form of TCR(V)$\mathrm{Ig}(\mathrm{C})$ hybrids expressed in myeloma cell lines (Gascoigne et al. 1987). Interestingly, only $\mathrm{V}_{\alpha}$ (TCR) $\mathrm{C}_{\mathrm{H}}(\mathrm{Ig})$ chimeras could be assembled or secreted as apparently normal immunological molecules (being expressed with light chains). Neither $\mathrm{V}_{\beta}$ (Gascoigne et al. 1987), $V_{\gamma}$, nor $V_{\delta}$ (R. Wallich et al.; I.A. MacNeil et al.; both unpubl.) gene segments could be expressed in that same context, suggesting that there is some structural barrier to proper folding. Another category of TCR-Ig chimeras, namely those of Karjalainen and co-workers (Traunecker et al. 1989) have also failed to produce proper heterodimers (with one exception; B. Malissen, pers. comm.). Recent reports of $\operatorname{Ig}(\mathrm{V})$ TCR(C) chimeras being expressed and having demonstrable antigen-binding activity (Z. Eshhar; Y. Kurosawa et al.; both pers. comm.) indicate that the reciprocal type of chimera works well. A number of groups have also tried to express soluble TCRs by truncation, that is, by placing a stop codon at the 


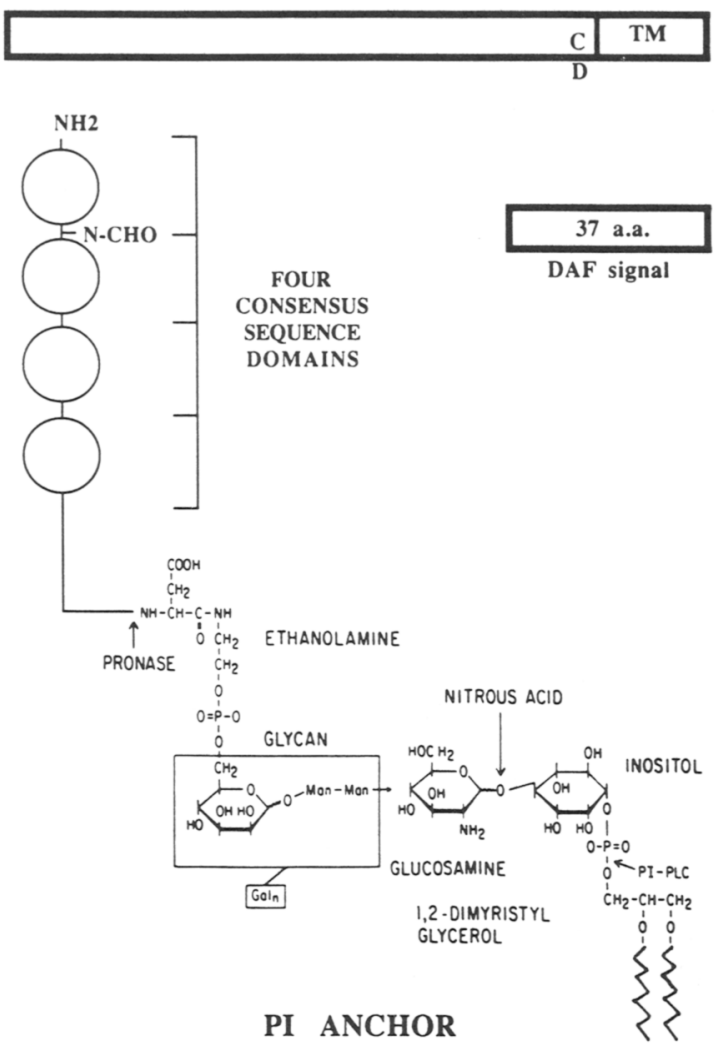

\section{B TCR}

\section{Alpha Chain}

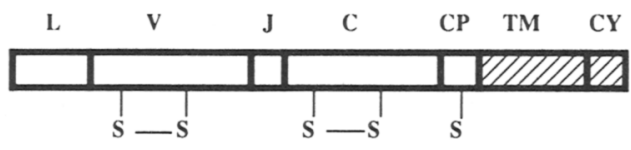

Beta Chain

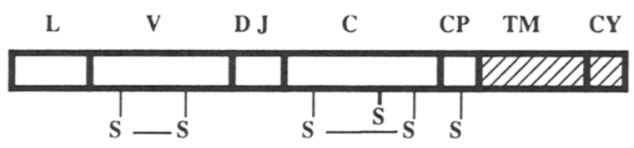

\section{TCR-DAF}

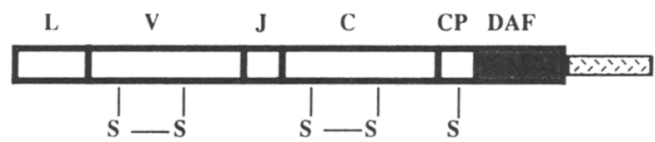

Figure 1. Schematic structure of PtdIns (PI)-anchored protein. $(A)$ Structure of membrane-bound DAF. During the maturation of DAF, the last 17 amino acids (TM), containing a highly hydrophobic domain, are proteolytically cleaved. The PtdIns moiety is then attached to the cystein (C). The last 37 amino acids at the carboxyl terminus of DAF that functions as a PtdIns-anchoring signal are highlighted $(\square)$. PtdIns is linked to the carboxyl terminus of DAF through glucosamine, glycan, and ethanolamine residues. PtdIns-PLC cleaves at the phosphodiester bond of the PtdIns moiety as indicated. (B) Structure of PtdIns-anchored TCR. The domain structure and disulfide bond of TCRs are indicated. In the PtdIns-anchored TCR the transmembrane and cytoplasmic domains are replaced with the PtdIns-anchoring signal. PtdIns-anchored expressed on the cell surface with the PtdIns moiety attached to the carboxyl terminus of the 20 amino acid residues remaining of the PtdIns-anchor signal. 
beginning of the transmembrane sequence (O. Acuto and E. Reinherz; K. Arai et al., both pers. comm.). In these cases, it appears that polypeptides are expressed, but there is no heterodimer formation. This is not an infrequent occurrence in truncation experiments, perhaps because of incorrect juxtaposition of the two chains and/or loss of important cell-trafficking signals (in the transmembrane sequence). Recently, through colleagues at Genentech, we became aware of the increasingly large list of surface proteins known to be lipid-linked (for review, see Ferguson and Williams 1988). All such proteins can be cleaved with a specific enzyme, phosphatidylinositol-specific-phospholipase C (PtdIns-PLC), to produce soluble forms. Caras et al. (1987) had shown that the carboxy-terminal 37 amino acids of decay accelerating factor (DAF) could serve as the signal sequence for the lipid-linked expression of a herpes simplex virus membrane protein. Thus, expression of TCR polypeptides as PtdIns-linked molecules might allow them to associate in the plane of a membrane to maximize heterodimer formation and to be cleaved off the surface of expressing cells to produce a soluble form. From a suggestion of P. Travers, we also included experiments with the carboxyl terminus of human placental alkaline phosphatase (HPAP) (Kam et al. 1985) because that PtdIns-linked molecule is normally expressed as a homodimer (DAF is a monomer). Thus, an HPAP "stem" structure may be more compatible with proper heterodimer formation.

Figure 1A shows the native form of DAF with the glycan-PtdIns tail. The enzyme PtdIns-PLC cleaves as indicated. Figure 1B shows schematics of the TCRDAF fusions with the TCR/HPAP chimeras being done in the same fashion. The characteristics of expression of this type is that a proform of the molecule is translated and that in the endoplasmic reticulum a portion of the carboxyl terminus is cleaved off (17 amino acids in the case of DAF and 23 amino acids in the case of HPAP; Micanovic et al. 1988) and an ethanolamine-carbohydrate-phosphatidylinositol linkage (Fig. 1A, from Ferguson and Williams 1988) is added to the new carboxyl terminus of the protein, which then makes its way to the cell surface.

With respect to TCR expression in both COS cells (for transient transfections) and Chinese hamster ovary (CHO) cells (for long-term transfectants), we found that in most cases single chains of the TCR could be expressed with either the HPAP or the DAF signal sequence with high efficiency (using an expression vector derived from pcDL-SR $\alpha 296$, Takebe et al. 1988) and cleaved off the surface of expressing cells with PtdIns-PLC (in early experiments, a gift from M. Low). Expression could be demonstrated by either the immunoprecipitation of surface-iodinated cells or fluorescence-tagging and analysis by microscopy or a fluorescence-activated cell sorter (FACS). Immunoprecipitation indicates the presence of both dimers and monomers in most cases (A. Lin et al.; B. Devaux et al.; both in prep.). Analysis of $\mathrm{CHO}$ cells transfected with both $\alpha$ and $\beta$ chains from the $2 \mathrm{~B} 4$ hybridoma modified with either the DAF or HPAP signal sequences was particularly revealing. As shown in Figure 2, stable transfectants could be isolated that coexpressed both $\alpha$ and $\beta$ chain determinants (A. Lin et al., in prep.). To demonstrate that heterodimers between $\alpha$ and $\beta$ were being formed that juxtapose $V_{\alpha}$ and $V_{\beta}$ determinants, we made use of the fact that preincubation of $2 \mathrm{~B} 4 \mathrm{TCR}$ bearing cells with the saturating amounts of anti-Va2B4 (A2B4-2 from Samelson et al. 1983) antibody abolished staining with the anti- $\mathrm{V}_{\beta} 3$ antibody (KJ25 from Pullen et al. 1988). This cross-blocking phenomenon is shown in Figure 3, showing $\beta^{-}$Jurkat cells (a gift from A. Weiss) transfected with normal $2 B 4 \alpha$ and $\beta$ chain genes as a control. In Figure 3A, the cells were stained with KJ25 (a hamster antibody) and visualized with fluorescinated anti-hamster antiserum. The presence of both negative and positive populations seen in Figure 3 is due to the nonclonal nature of this cell line. In Figure $3 \mathrm{~B}$, this same cell line has been pretreated with anti2B4 $\left(\mathrm{V}_{\alpha}\right)$ antibody both prior to and during the $\mathrm{KJ} 25$ staining, effectively blocking all anti- $\mathrm{V}_{\beta}$ reactivity. This same effect can be seen with $\mathrm{CHO}$ cells transfected with either $\alpha$ DAF and $\beta$ DAF chimeras or $\alpha$ HPAP and $\beta$ HPAP constructs (Fig. 3C, D), indicating that approximately $90 \%$ of the $2 \mathrm{~B} 4 \beta$-chain polypeptides are being expressed as heterodimers with the complementary $\alpha$ chain (A. Lin et al., in prep.). Mass culture, cleavage with PtdIns-PLC, and isolation on antibody columns also indicates that most of the TCR

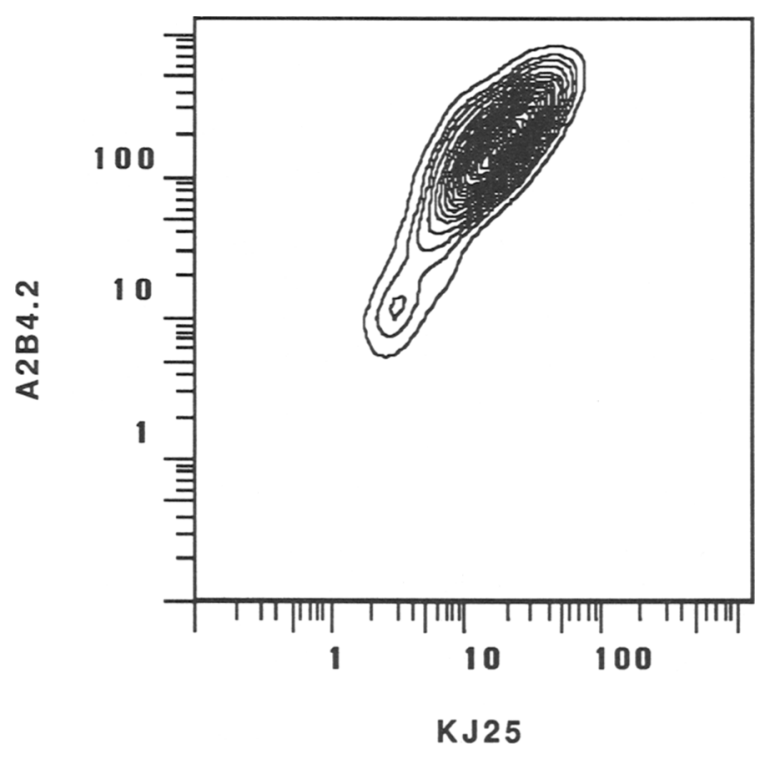

Figure 2. Coexpression of PtdIns-anchored TCR $\alpha$ and $\beta$ chains on the cell surface. CHO cells were transfected with a plasmid containing the sequences encoding TCR $\alpha$ and $\beta$ chains with PtdIns-anchor signal sequences (A. Lin et al., in prep.). The stable transfectants were analyzed for surface expression of $\alpha$ and $\beta$ chains, with FACS, by sequentially staining antibodies $\mathrm{KJ} 25$ (anti- $\mathrm{V}_{\beta} 3$ ) and biotinylated A2B4.2 (anti- $V_{\alpha} 11$ ) with fluorescein-isothyocyanate (FITC)-conjugated goat anti-mouse immunoglobulin and streptavidin as second antibodies, respectively. The data is plotted as log fluorescent intensity in arbitrary units. 

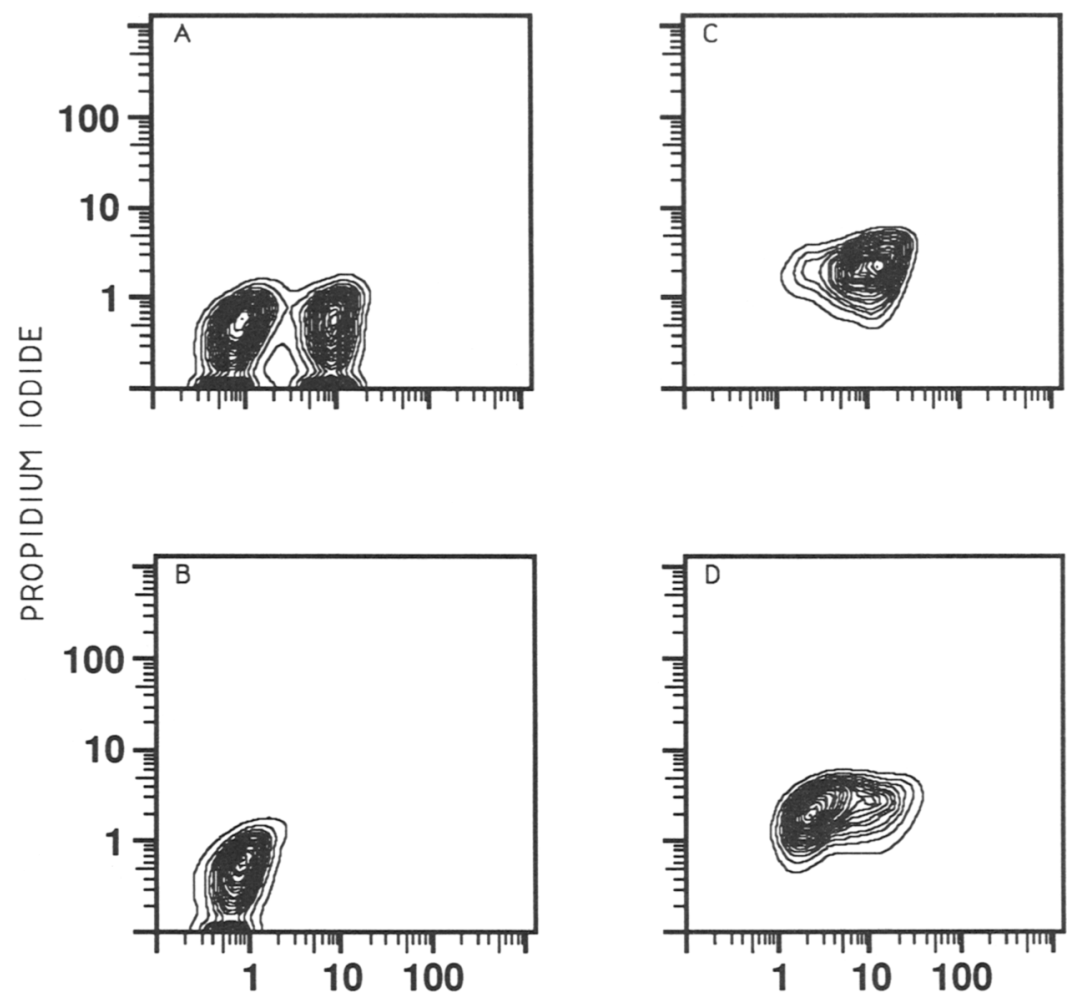

$\mathrm{KJ} 25$

Figure 3. Blocking of KJ25 by A2B4.2 on the staining of cell-surface PtdIns-anchored TCR. $\beta^{-}$Jurkat with surface expression of functional 2B4 TCR $\alpha \beta(A$ and $B)$ and $\mathrm{CHO}$ transfectants $(C$ and $D)$ (as described in Fig. 2) were stained with antibody KJ25, with $(B$ and $D)$ or without $(A$ and $B$ ) pretreatment with A2B4.2. Following binding of FITC-conjugated goat anti-mouse immunoglobulin, cells were analyzed on the FACS. The data are plotted as log fluorescent intensity in arbitrary scale. CHO has higher fluorescent background than Jurkat as indicated in the propidium iodide staining (A. Lin et al., in prep.)

protein expressed in this fashion is in the form of heterodimers (data not shown). Currently, we are able to purify hundreds of micrograms of soluble receptor. Perhaps the most crucial test is whether TCR expressed in this way can bind to antigen/MHC complexes. Preliminary experiments suggest that it can, but signals are very low and the amount of fluctuation is high.

\section{Selection of the T-cell Repertoire In Vivo}

How the T-cell repertoire is shaped in the thymus has long been an interesting but controversial area of immunology. In particular, the concept of "positive selection" or rather the selective export to the periphery of $\mathrm{T}$ cells that are best able to interact with self-MHC molecules has been the subject of much controversy. Whereas many laboratories have seen this type of selection in irradiated recipient strains (Bevan 1977; Fink and Bevan 1978; Kappler and Marrack 1978; Sprent 1978; von Boehmer et al. 1978; Zinkernagel et al. 1978; Singer et al. 1981), others have not (Matzinger and Mirkwood 1978; Stockinger et al. 1980; Ishii et al. 1981). Governman et al. (1986) dismissed evidence of positive selection as being the result not of thymic selection but of preferential T-cell expansion in the periphery. In addition, the nature of the experiments performed was constrained by the facts that mice were heavily manipulated (e.g., irradiated); no single TCR could be followed but only reactivity to particular antigens that must involve many TCRs and probably many epitopes as well; the signal being followed is relatively low because of the small number of cells with a given reactivity at any one time; and because the number of cells being followed is a small fraction of the total, the opportunity to study the biochemistry and physiology of this phenomenon is nil.

The applicability of the transgenic mouse technology (Hogan et al. 1986) to these problems is very clear in that with the proper expression of a given TCR $\alpha \beta$ a large fraction of the $\mathrm{T}$ cells in a given individual would be of uniform specificity and subject to the same influences. In this case, different MHC molecules, antigens, and other forces could all be used to modulate expression. The power of this approach can be seen in Figure 4. In this experiment, $\alpha$ - and $\beta$-chain genomic constructs for $2 \mathrm{~B} 4$, a helper T-cell hybridoma that recognizes a fragment of cytochrome $c$ complexed to the I-E $\mathrm{E}^{\mathrm{K}}$ molecule (Hedrick et al. 1982; Samelson et al. 1983), have been introduced into the mouse germ-line and back-crossed extensively to B10 mice to remove minor lymphocyte-stimulating antigen $\left(\mathrm{Mls}-2^{\mathrm{A}} / 3^{\mathrm{A}}\right)$ ef- 
A

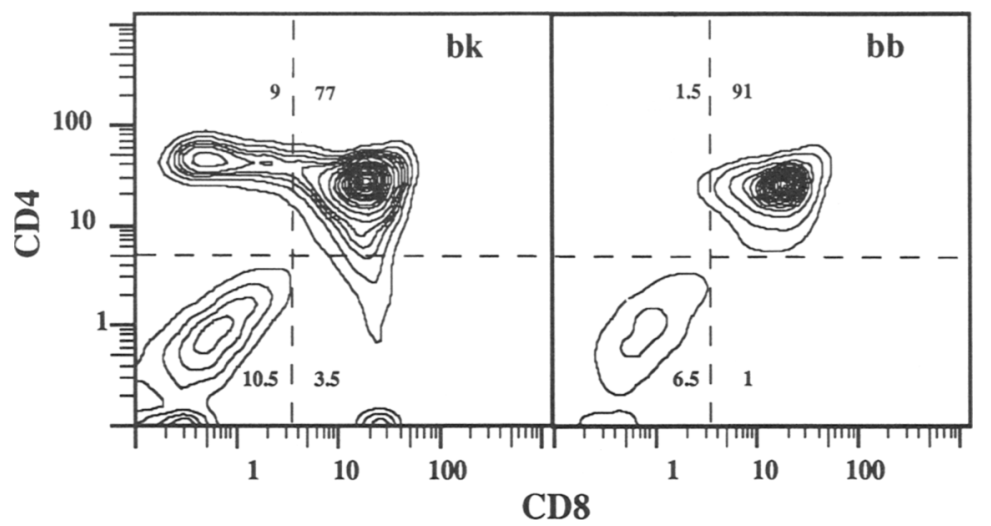

B

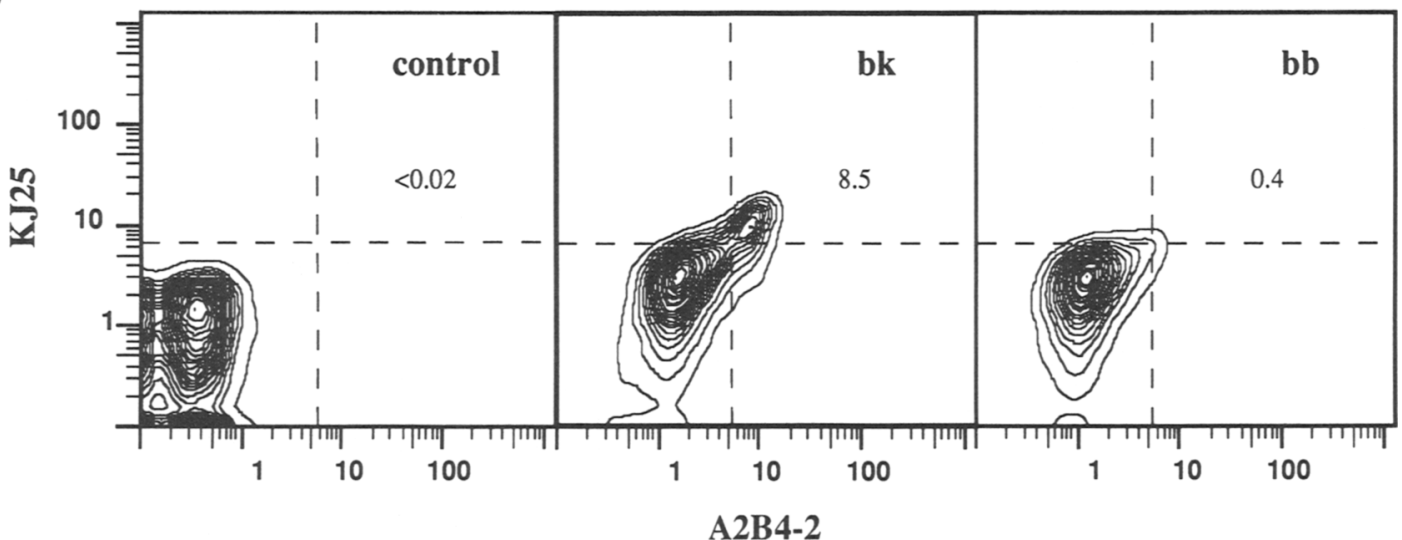

Figure 4. Staining of thymocytes from $\mathrm{H}-2^{\mathrm{kxb}}$ versus $\mathrm{H}-2^{b} \alpha \beta$ transgenic mice. $(A)$ Thymocytes from an $\mathrm{H}-2^{\mathrm{kxb}}$ (left) and an $\mathrm{H}-2^{b}$ (right) $\alpha \beta$ transgenic mouse were stained with directly conjugated anti-CD4-phycoerythrin (PE) and the anti-CD8-FITC. The numbers on each profile indicate the percentage of total thymocytes with each phenotype. $(B)$ Thymocytes from an $H-2^{k \times b}$ nontransgenic control (left), an $\mathrm{H}-2^{\mathrm{k} \times \mathrm{b}} \alpha \beta$ transgenic (center), and an $\mathrm{H}-2^{\mathrm{b}} \alpha \beta$ transgenic (right) were stained with $\mathrm{KJ} 25$ (anti- $\mathrm{V}_{\beta} 3$ ) followed by anti-hamster Texas Red plus directly conjugated A2B4-2-FITC. The number on each profile indicates the percentage of cells staining brightly with both $\alpha$ and $\beta$ chain antibodies. (Reprinted, with permission, from Berg et al. 1989b.)

fects (Berg et al. 1988, 1989b; Ivars et al. 1988). In this case, the IgH enhancer (Banerji et al. 1983; Gillies et al. 1983) has been used in place of the native $\alpha$ and $\beta$ enhancers to achieve a high level of expression (Berg et al. 1988; Ivars et al. 1988). Figure 4A shows the very different CD4/CD8 thymic staining patterns of $\alpha \beta$ transgenics having the appropriate $\mathrm{MHC}\left(\mathrm{H}-2^{\mathrm{k}}\right)$ versus those lacking $\mathrm{I}-\mathrm{E}$ expression altogether $\left(\mathrm{H}-2^{\mathrm{b}}\right)$. Thymic expression on a $\left(\mathrm{H}-2^{k} \times \mathrm{H}-2^{k}\right) F_{1}$ bK background is relatively normal, whereas the $\mathrm{H}-2^{\mathrm{b}} \mathrm{BB}$ pattern is distinctly abnormal, with an obviously arrested development at the double-positive stage $\left(\mathrm{CD}^{-} 8^{-}\right.$) of thymocyte differentiation, as indicated by the greatly reduced numbers of single positive $\left(\mathrm{CD} 4^{+}\right.$or $\mathrm{CD} 8^{+}$) thymocytes. This failure of $\alpha \beta$ transgene-bearing cells to mature in the wrong $\mathrm{MHC}$ environment is also seen in Figure $4 \mathrm{~B}$, in this case staining with antibodies directed at both chains of the TCR transgenes. Here we see that $\mathrm{H}-2^{\mathrm{K}}$ individuals have a large fraction of $\alpha \beta-2 \mathrm{~B} 4$ dull cells (in the double-positive compartment) and also significant numbers of $\alpha \beta$ bright cells as well (corresponding to the single-positive compartment). These transgene-TCR dull cells are just as visible in the $\mathrm{H}-2^{\mathrm{b}}$ transgenic thymus, but the bright $\alpha \beta$-staining cells are not. Peripheral expression follows the same pattern, with $\mathrm{H}-2^{\mathrm{K}}$ mice having many more $\alpha \beta$ staining cells and a much higher fraction of cytochrome $c$ reactive cells than $\mathrm{H}-2^{\mathrm{b}}$ littermates, as measured in limiting dilution interleukin-2 (IL-2) assays of antigen-naive mice (Berg et al. 1989b). Also of interest is the heavy bias toward CD4 expression seen in $\alpha \beta$ mice, which have $\mathrm{H}-2^{\mathbf{k}}$, although the $2 B 4$ hybridoma lacks CD4 (or CD8) expression. This suggests that the original $T$ cell expressing the $2 \mathrm{~B} 4$ antigen receptor was in fact $\mathrm{CD}^{+}$and that expression of this molecule was lost sometime after fusion with BW5147. In fact, very few T-cell fusions have persistent CD4 or CD8 expression. Together with the data of von Boehmer and colleagues (Kisielow et al. 1988b) and Loh and colleagues (Sha et al. 1988a,b) with class I MHC-specific transgenics preferentially expressing CD8, this data also indicates that the MHC class preference of a TCR predetermines CD4 or CD8 expression. In addition, to characterize this phenomenon further, we wish also to address the following questions: Is the I-E molecule responsible for this effect? Is thymic expression of I-E necessary and sufficient? What cells in the thymus are most important for positive selection? 


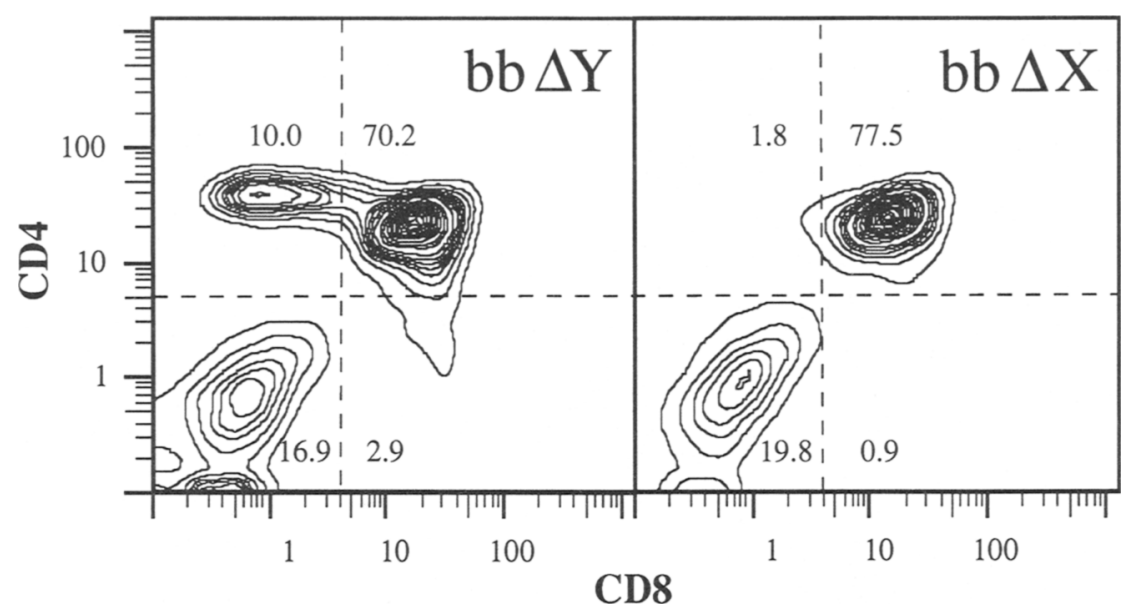

Figure 5. CD4 versus $\mathrm{CD} 8$ staining of thymocytes from $\Delta \mathrm{X}$ and $\Delta \mathrm{Y} \alpha \beta$ transgenic mice. Thymocytes for $\alpha \beta$ transgenic mice of two MHC types $\left(\mathrm{H}-2^{\mathrm{b}}+\Delta \mathrm{Y}\right.$ and $\left.\mathrm{H}-2^{\mathrm{b}}+\Delta \mathrm{X}\right)$ were stained with anti-CD4 and anti-CD8. The percentage of thymocytes in each subset is indicated on each profile. Cells were stained with directly conjugated anti-CD4-PE and anti-CD8-FITC. (Reprinted, with permission, from Berg et al. 1989b.)

This we were able to do with the help of $C$. Benoist and D. Mathis, who kindly provided us with lines of transgenic mice for expressing different versions of $\mathrm{E}_{\alpha}{ }^{k}$, the gene defective in $\mathrm{H}-2^{\mathrm{b}}$ mice and several other I-E ${ }^{-}$strains (Mathis et al. 1983; Le Meur et al. 1985; van Ewijk et al. 1988). We will focus here on the $\Delta Y$ mice, which on a $\mathrm{H}-2^{\mathrm{b}}$ background express I-E in the cortical epithelium of the thymus with approximately $1 \%$ of normal expression in the medulla (and none elsewhere) and the $\Delta \mathrm{X}$ mice, which express I-E only in the medullary region of the thymus (van Ewijk et al. 1988 ). Crossing our $2 \mathrm{~B} 4 \alpha \beta$ mice with these $\mathrm{E}_{\alpha}{ }^{\mathrm{k}}$ transgenics produced very clear effects as shown in Figure 5 . The first panel shows the CD4/CD8 pattern of thymocytes staining in the thymocytes of $\triangle \mathrm{Y} \mathrm{BB}$ mice, whereas the second shows the analogous data for $\triangle \mathrm{X} B B$ mice. It is thus clear that I-E expression in the cortical epithelium is sufficient to rescue almost entirely the positive selection in these mice (Fig. 4A), whereas medullary expression has no discernible effect (Berg et al. 1989b). Therefore, the basic tenets of positive selection are upheld in that the original restricting element is the important molecule in mediating this effect (for complementary data in a class I MHC-dependent system, see Kisielow et al. 1988a). In addition, these results also offer very strong support that the experiments of Sprent and his colleagues showing the importance of thymic epithelial cells in this phenomenon (Lo and Sprent 1986; Singer 1988; Sprent et al. 1988) are vindicated.

\section{Negative Selection}

The other major selective criterion being applied in the thymus involves the removal of self-reactive $T$ cells. Ample evidence for this phenomenon involving the death of such cells has been obtained making use of the Mls-mediated self-reactivity model (Kappler et al.
1987, 1988; MacDonald et al. 1988; Pullen et al. 1988; Pircher et al. 1989; White et al. 1989). These data are consistent with one another and indicate that Mls-reactive cells are absent from the mature single-positive population $\left(\mathrm{CD} 4^{+}\right.$or $\left.\mathrm{CD} 8^{+}\right)$and the numbers in the double-positive $\mathrm{CD} 4^{+} 8^{+}$compartments are not obviously reduced. The limitations of these studies is inherent in the phenomenology of the Mls loci and the related Staphylococcus enterotoxin effects, which seem specific only for the germ-line-encoded residues of specific $V_{\beta}$ molecules and apparently do not involve processed antigens (Janeway et al. 1989). Recent studies (Dellabona et al., this volume) further indicate that Staphylococcus enterotoxin B is not affected by mutations in $\mathrm{I}-\mathrm{A}_{\alpha}$, which disrupt lysozyme peptide binding, but instead is only disrupted by mutations that point outward (from the putative $\alpha$ helix, that is, away from the peptide-binding groove). Thus, Mls and Staphylococcus enterotoxin reactivities are interesting phenomena, but their relevance to the problem of selftolerance is questionable.

The ability of the Mls deletion data to be generalized has come under further scrutiny with the advent of recent experiments examining the deletion of self-reactive cells in animals transgenic for self-reactive TCRs. In both examples, the $H Y+D^{b}$ system (Kisielow et al. $1988 \mathrm{~b}$ ) and the anti- $\mathrm{L}^{\mathrm{d}}$ model (Sha et al. 1988b) $\mathrm{T}$ cells bearing both $\alpha$ and $\beta$ TCR transgenes are specifically deleted from animals that express those targets, but in each case the thymic double-positive compartment is severely affected (as well as the mature single-positive cells). Thus, the timing of negative selection appears to be very early in or even before the $\mathrm{CD} 4^{+} 8^{+}$compartment in those systems. In the $2 \mathrm{~B} 4$ system, we have encountered our own experiences with negative selection based on Mls reactivity, which helps to resolve some of these issues (Berg et al. 1989a). In particular, there was a quantitative removal of cells expressing a 
high level of the $2 \mathrm{~B} 4 \beta$ chain because of the combination of its $\mathrm{V}_{\beta} 3$ component and the Mls $-2^{\mathrm{A}} / 3^{\mathrm{A}}$ genotype $(\mathrm{C} 3 \mathrm{H} / \mathrm{HeJ})$ of one of the parental strains (as defined by Abe et al. 1988; Fry and Matis 1988; Pullen et al. 1988, 1989 ). We found deletion of mature $2 \mathrm{~B} 4 \beta$-positive cells to be evident in the thymuses of both $2 \mathrm{~B} 4 \mathrm{TCR} \alpha \beta$ mice, as well as $2 \mathrm{~B} 4 \beta$ mice. What was interesting, however, was the very different phenotype exhibited by these two types of mice, both of which were undergoing massive and efficient negative selection. The thymic CD4/CD8 profile is shown in Figure 6, indicating that the $\beta$ mice had a very similar arrest in the doublepositive stage as seen in the $\mathrm{H}-2^{\mathrm{b}} \alpha \beta 2 \mathrm{~B} 4$ transgenics in Figure 4 or in normal mice undergoing Mls-mediated deletion (Kappler et al. 1987, 1988). In contrast, the $\alpha \beta$ mice that deleted $\mathrm{V}_{\beta} 3$ had a greatly reduced percentage of double-positive cells ( $2 \%$ of the total) and overall less than $1 / 10$ of the normal number of thymocytes, exactly as reported previously by Kisielow et al. (1988b) for $\mathrm{HY}+\mathrm{D}^{\mathrm{b}}$ and as seen in the high-expressing mice of Sha et al. (1988b). Figure 6 shows a histogram of the absolute numbers of $\mathrm{CD}^{+} 8^{+}$cells in these mice, making even clearer the conclusion that the presence of $\operatorname{TCR} \alpha \beta$ transgenes greatly augments the affects of negative selection, perhaps by speeding up the kinetics of T-cell differentiation and selection in the thymus (Berg et al. 1989a). This, in fact, is predictable from the observations that the TCR $\alpha$ chain is the last TCR to be rearranged and expressed during thymic development, and thus the presence of a rearranged $\alpha$ chain is bound to have an effect on maturation of at least some $\mathrm{T}$ cells.
In fact, data (B. Fazekas de St. Groth et al., in prep.) indicate that TCR $\alpha$ transgenics express $\operatorname{TCR} \alpha \beta$ fully 2 days before normal (day 15 versus day 17) in fetal mice and at inappropriately high levels. This effect may be due to the absence of normal controlling elements in experiments to date, especially the silencer regions $3^{\prime}$ of $\mathrm{C}_{\alpha}$, recently described by Winoto and Baltimore (this volume). Another important point is that this study of negative selection shows the essential equivalence of Mls-mediated deletion versus antigen plus MHC (Kisielow et al. 1988b) and alloreactive (Sha et al. $1988 \mathrm{~b}$ ) deletion in $\alpha \beta$ transgenic mice. This indicates that Mls-mediated deletion is, in fact, a valid model for the developmental aspects of self-tolerance.

A third conclusion from this study is that death by negative selection in $\alpha \beta$ transgenics is not the same as death by absence of positive selection in any of the three $\alpha \beta$ transgenic systems discussed above. This is indicated in Figure 7, which compares 2B4 $\alpha \beta$ expression on $\mathrm{H}-2^{\mathrm{b}}$ and $\mathrm{H}-2^{\mathrm{k}}$ background transgenics versus negative selection of these same transgenes because of Mls- $2^{\mathrm{A}} / 3^{\mathrm{A}}$-mediated deletion. Thus, although both positive and negative selection are first evident at the same time normally (i.e., toward the end of the doublepositive stage of differentiation) and seem to occur in the same location in the thymus (i.e., the cortex), the effect of negative selection on $\alpha \beta$ mice is phenotypically much more severe. One explanation for this might be that self-reactive $\alpha \beta$ transgenic cells arise and are dispatched more quickly; the mechanism of death by negative selection in this instance might be kinetically

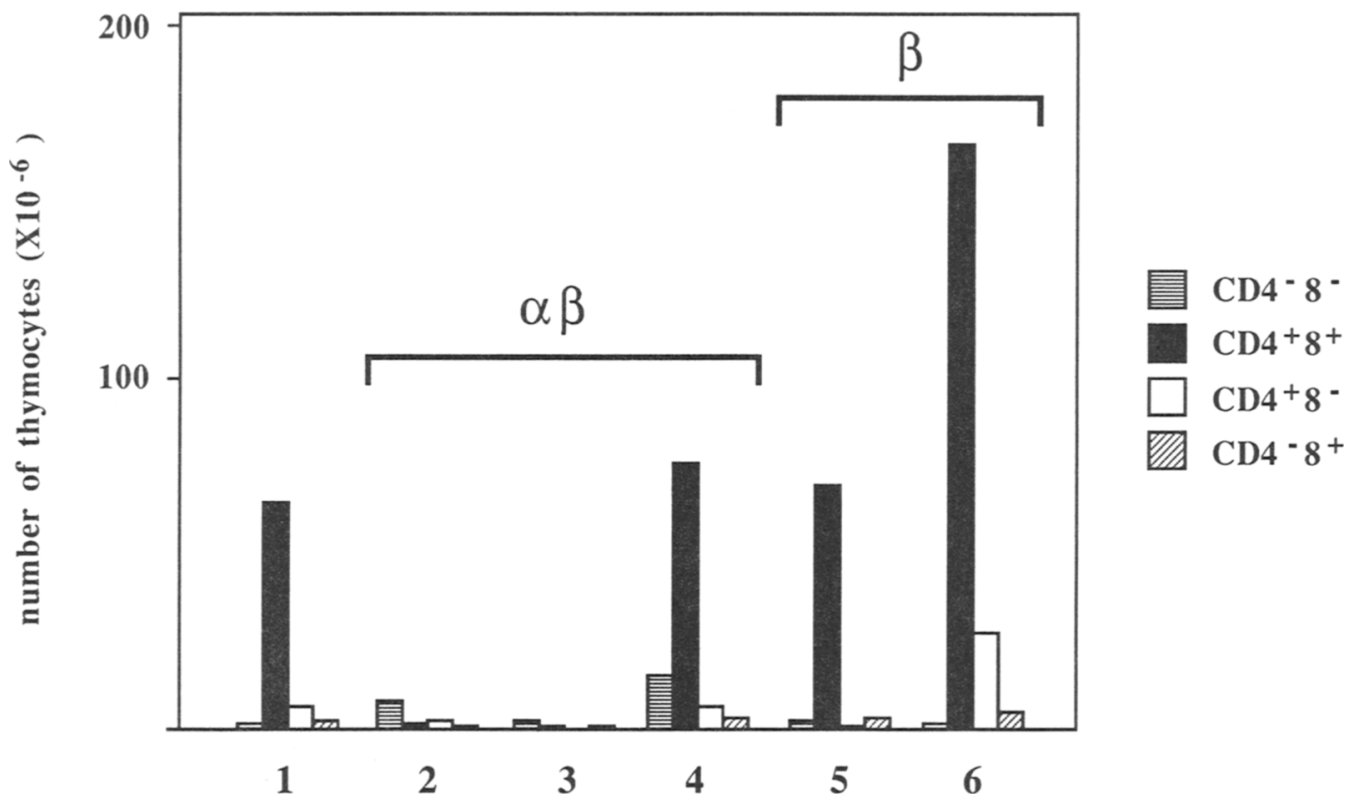

Figure 6. The effects of negative selection on thymocytes of $\alpha \beta$ versus $\beta$ transgenic mice are shown graphically (Berg et al. 1989a). The total number of thymocytes of each subset $\left(\mathrm{CD} 4^{-} 8^{-}, \mathrm{CD}^{+} 8^{+}, \mathrm{CD}^{+} 8^{-}, \mathrm{CD}^{-} 8^{+}\right)$are indicated for $(1)$ a nontransgenic control, (2) an anti- $\left[\mathrm{D}^{\mathrm{b}}+\mathrm{HY}\right] \alpha \beta$ transgenic (Kisielow et al. 1988a), (3) an anti- $\left[\mathrm{H}-2^{\mathrm{k}}+\mathrm{Mls}-2^{\mathrm{a}}\right.$ and $/$ or $\left.-3^{\mathrm{a}}\right] \alpha \beta$ transgenic, (4) a non- $\mathrm{V}_{\beta} 3$ deleting $\alpha \beta$ transgenic, (5) an anti-[H-2 ${ }^{\mathrm{k}}+\mathrm{Mls}-2^{\mathrm{a}}$ and $/$ or $\left.-3^{\mathrm{a}}\right] \beta$ transgenic, and (6) a non- $\mathrm{V}_{\beta} 3-\mathrm{deleting} \beta$ transgenic. Note the severe reduction in $\mathrm{CD} 4{ }^{+} 8^{+}$cells in the $\alpha \beta$ transgenics compared with the twofold reduction (back to normal levels) in the $\beta$ transgenic. 


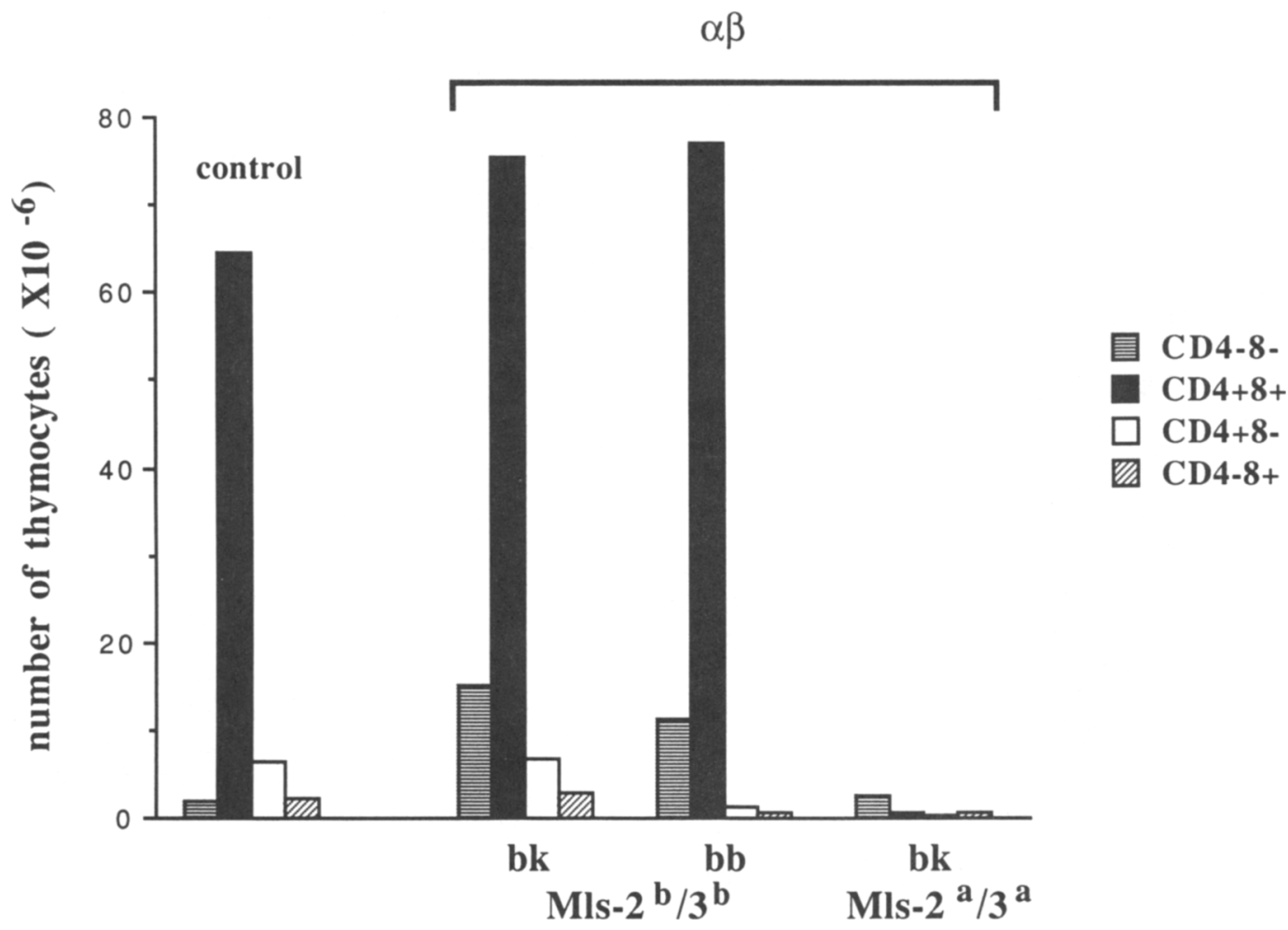

Figure 7. The effects of positive selection versus negative selection on thymocytes of $\alpha \beta$ transgenic mice. The total number of thymocytes of each subset $\left(\mathrm{CD}^{-} 8^{-}, \mathrm{CD}^{+} 8^{+}\right.$, and $\left.\mathrm{CD} 4^{-} 8^{+}\right)$are indicated for four mice: one nontransgenic control and three $\alpha \beta$ transgenics. From left to right, the $\alpha \beta$ transgenics are an $\mathrm{H}-2^{\mathrm{kxb}}, \mathrm{Mls}-2^{\mathrm{b}}$ and $-3^{\mathrm{b}}$ (undergoing positive selection), an $\mathrm{H}-2^{\mathrm{b}}$, Mls- $2^{\mathrm{b}}$ and $-3^{b}$ (no significant positive selection), and an $\mathrm{H}-2^{\mathrm{kxb}}$, Mls-2 $2^{\mathrm{a}}$ and/or $-3^{\mathrm{a}}$ (undergoing negative selection). Note the radically different phenotype resulting from the absence of positive selection compared with negative selection.

much faster, mediated either by another cell type ( $\gamma \delta$ killers?) or by some "active" principal. Thus, $\alpha \beta$ transgenics appear to be illustrating some significant mechanistic differences between positive and negative selection in the thymus.

\section{CONCLUDING REMARKS}

Much as issues involving the generation of antibody diversity began to be resolved in the late 1970s, the field of T-cell recognition and selection is beginning to coalesce around the specific molecules and the genes responsible for them. Unlike the antibody "problem," however, knowledge of TCR or MHC genes alone has not been sufficient to explain much of the phenomena important to the T-cell field. Instead, these issues have been starting points in a progressive narrowing of options toward what we hope will be a resolution of some of them in the near future. The successful expression of soluble TCRs will help to bridge the gap between our essentially circumstantial knowledge of T-cell antigen/ MHC interactions to date and a more complete biochemical and ultimately structural appreciation for what is going on. More distant is the expectation that mice transgenic for specific TCRs will not only confirm and extend classical experiments on positive and negative selection but will be the ideal departure point for mechanistic studies of these phenomena.

\section{ACKNOWLEDGMENTS}

We wish to thank Dr. J. Bangs for advice concerning PtdIns-linked proteins, Angela Nervi for excellent technical assistance, and Brenda Robertson for preparation of the manuscript. We also thank National Institutes of Health for grant support. M.M.D. is a scholar of the Pew Foundation, L.J.B. is a fellow of the Leukemia Society of Anemia, and A.L. was previously a fellow of the Cancer Research Institute and is now supported by the Howard Hughes Medical Institute. B.F.de S.G. was supported by an Irvington House postdoctoral fellowship and is now supported by a fellowship from the Medical Research Council of $\mathrm{Au}$ stralia. P.J.B. was supported by an American Cancer Society postdoctoral fellowship, and J.F.E. is a centennial fellow of the Medical Research Council of Canada.

\section{REFERENCES}

Abe, R., M.S. Vacchio, B. Fox, and R. Hodes. 1988. Preferential expression of the T-cell receptor $\mathrm{V}_{\beta} 3$ gene by Mls ${ }^{\mathrm{c}}$ reactive T cells. Nature 335: 827.

Banerji, J., L. Olson, and W. Schaffner. 1983. A lymphocytespecific cellular enhancer is located downstream of the joining region in immunoglobulin heavy chain genes. Cell 33: 729.

Berg, L.J., B. Fazekas de St. Groth, A.M. Pullen, and M.M. Davis. 1989a. Phenotypic differences between $\alpha \beta$ and $\beta$ T 
cell receptor transgenic mice undergoing negative selection. Nature 340: 559.

Berg, L.J., A.M. Pullen, B. Fazekas de St. Groth, D. Mathis, C. Benoist, and M.M. Davis. 1989b. Antigen/MHC specific $\mathrm{T}$ cells are preferentially exported from the thymus in the presence of their MHC ligand. Cell 58: 1035.

Berg, L.J., B. Fazekas de St. Groth, F. Ivars, C.C. Goodnow, S. Gilfillan, H.-J. Garchon, and M.M. Davis. 1988. Expression of T-cell receptor alpha-chain genes in transgenic mice. Mol. Cell. Biol. 8: 5459.

Bevan, M. 1977. In a radiation chimera, host $\mathrm{H}-2$ antigens determine immune responsiveness of donor cytotoxic $\mathrm{T}$ cells. Nature 269: 417 .

Bjorkman, P.J., M.A. Saper, B. Samraoui, W.S. Bennett, J.L. Strominger, and D.C. Wiley. 1987a. Structure of the human class I histocompatibility antigen, HLA-A2. Nature 329: 506 .

- $1987 \mathrm{~b}$. The foreign antigen binding site and $\mathrm{T}$ cell recognition regions of class I histocompatibility antigens. Nature 329: 512.

Brown, J.H., T. Jardetzky, M.A. Saper, B. Samraoui, P.J. Bjorkman, and D.C. Wiley. 1988. A hypothetical model of the foreign antigen binding site of Class II histocompatibility molecules. Nature 332: 845 .

Caras, I.W., G.N. Weddell, M.A. Davitz, V. Nussenzweig, and D.W. Martin, Jr. 1987. Signal for attachment of a phospholipid membrane anchor in decay accelerating factor. Science 238: 1280 .

Chothia, C., D.R. Boswell, and A.M. Lesk. 1988. The outline structure of T-cell $\alpha \beta$ receptor. EMBO J. 7: 3745.

Claverie, J.M., A. Prochnicka-Chalufour, and L. Bougueleret. 1989. Implications of a Fab-like structure for the T-cell receptor. Immunol. Today 10: 10.

Davis, M.M. and P.J. Bjorkman. 1988. T cell antigen receptor genes and T cell recognition. Nature 334: 395 .

Dembic, Z., W. Haas, S. Weiss, J. McCubrey, H. Kiefer, H. von Boehmer, and $H$. Steinmetz. 1986. Transfer of specificity by murine alpha and beta $\mathrm{T}$ cell receptor genes. Nature 320: 232.

Ferguson, M.A.J. and A. Williams. 1988. Cell-surface anchoring of proteins via glycosylphosphatidylinositol structures. Annu. Rev. Biochem. 57: 285.

Fink, P.J. and M.J. Bevan. 1978. H-2 antigens at the thymus determine lymphocyte specificity. J. Exp. Med. 148: 766 .

Fry, A.M. and L.A. Matis. 1988. Self-tolerance alters T-cell receptor expression in an antigen-specific MHC restricted immune system. Nature 335: 830 .

Gascoigne, N.R.M., C. Goodnow, K. Dudzik, V.T. Oi, and M.M. Davis. 1987. Secretion of a chimeric T-cell receptorimmunoglobulin protein. Proc. Natl. Acad. Sci. 84: 2936.

Gillies, S.D., S.L. Morrison, V.T. Oi, and S. Tonegawa. 1983. A tissue-specific transcription enhancer element is located in the major intron of a rearranged immunoglobulin heavy chain gene. Cell 33: 717 .

Governman, J., T. Hunkapiller, and L. Hood. 1986. A speculative view of the multicomponent nature of $\mathrm{T}$ cell antigen recognition. Cell 45: 475 .

Hedrick, S.M. L.A. Matis, T.T. Hecht, L.E. Samelson, D.L. Longo, E. Heber-Katz, and R.H. Schwartz. 1982. The fine specificity of antigen and la determinant recognition by $T$ cell hybridoma clones specific for cytochrome $c$. Cell 30: 141 .

Hogan, B., F. Costantini, and E. Lacy. 1986. Manipulating the mouse embryo: A laboratory manual. Cold Spring Harbor Laboratory, Cold Spring Harbor, New York.

Ishii, N., C.N. Baxevanis, Z.A. Nagy, and J. Klein. 1981 Responder $\mathrm{T}$ cell depleted of alloreactive cells react to antigen presented on allogenic macrophages from nonresponder strains. J. Exp. Med. 154: 978.

Ivars, F., L.J. Berg, B. Fazekas de St. Groth, C.C. Goodnow, H.-J. Garchon, S. Gilfillan, and M.M. Davis. 1988. The expression of T cell receptor $\alpha$ chain genes in transgenic mice. In The $T$ cell receptor (ed. M.M. Davis and J. Kappler), p. 187. A.R. Liss, New York.

Janeway, C.A., Jr., J. Yagi, P.J. Conrad, M.E. Katz, B. Jones, S. Vroegop, and S. Buxser. 1989. T-cell responses to Mls and to bacterial proteins that mimic its behavior. Immunol. Rev. 107: 60 .

Kam, W. E. Clauser, Y.S. Kim, Y.W. Kan, and W.J. Rutter. 1985. Cloning, sequencing, and chromosomal localization of human term placental alkaline phosphatase cDNA. Proc. Natl. Acad. Sci. 82: 8715.

Kappler, J.W. and P. Marrack. 1978. The role of H-2 linked genes in helper T cell function. J. Exp. Med. 148: 1510.

Kappler, J.W., N. Roehm, and P. Marrack. 1987. T cell tolerance by clonal elimination in the thymus. Cell 49: 263 .

Kappler, J.W., U. Staerz, J. White, and P.C. Marrack. 1988. Self-tolerance eliminates $\mathrm{T}$ cells specific for Mls-modified products of the major histocompatibility complex. Nature 332: 35

Kisielow, P., H.S. Teh, H. Bluthmann, and H. von Boehmer. 1988a. Positive selection of antigen-specific $T$ cells in thymus by restricting MHC molecules. Nature 335: 730.

Kisielow, P., H. Bluthmann, U.D. Staerz, M. Steinmetz, and H. von Boehmer. 1988b. Tolerance in $T$ cell receptor transgenic mice involves deletion of nonmature $\mathrm{CD}^{+} 8^{+}$ thymocytes. Nature 333: 742.

Le Meur, M., P. Gerlinger, C. Benoist, and D. Mathis. 1985. Correcting an immune response deficiency by creating $\mathrm{E}_{\alpha}$ gene transgenic mice. Nature 316: 38 .

Lo, D. and J. Sprent. 1986. Identity of cells that imprint H-2 restricted T cell specificity in the thymus. Nature 319: 672 .

MacDonald, H.R., R. Schneider, R.K. Lees, R.C. Howe, H. Acha-Orbea, H. Festenstein, R.M. Zinkernagel, and H. Hengartner. 1988. T cell receptor $V_{\beta}$ use predicts reactivity and tolerance to $\mathrm{Mls}^{\mathrm{a}}$-encoded antigens. Nature 332: 40 .

Mathis, D., C. Benoist, V. Williams, M. Kanter, and H. McDevitt. 1983. Several mechanisms can account for defective $\mathrm{E}_{\alpha}$ expression in different mouse haplotypes. Proc. Natl. Acad. Sci. 80: 273.

Matzinger, P. and G. Mirkwood. 1978. In a fully H-2 incompatible chimera, $T$ cells of donor origin can respond to minor histocompatibility antigens in association with either donor or host H-2 type. J. Exp. Med. 148: 84 .

Micanovic, R., C.A. Bailey, L. Brink, L. Gerber, Y.-C.E. Pan, J.D. Hulmes, and S. Udenfriend. 1988. Aspartic acid-48 of nascent placental alkaline phosphatase condenses with a phosphatidylinositol glycan to become the carboxyl terminus of the mature enzyme. Proc. Natl. Acad. Sci. 85: 1398.

Minami, Y., A.M. Weissmann, L.E. Samelson, and R.D. Klausner. 1987. Building a multichain receptor: Synthesis, degradation, and assembly of the T-cell antigen receptor. Proc. Natl. Acad. Sci. 84: 2688.

Pircher, H., T.W. Mak, R. Lang, W. Balhausen, E. Ruedi, H. Hengartner, R. Zinkernagel, and K. Burki. 1989. T cell tolerance to $\mathrm{Mls}^{\mathrm{a}}$ encoded antigens in $\mathrm{T}$ cell receptor $\mathrm{V}_{\beta} 8.1$ chain transgenic mice. $E M B O J$. 8: 719 .

Pullen, A.M., P. Marrack, and J.W. Kappler. 1988. The T cell repertoire is heavily influenced by tolerance to polymorphic self-antigens. Nature 335: 796.

. 1989. Evidence that Mls-2 antigens which deplete $\mathrm{V}_{\beta} 3^{+} \mathrm{T}$ cells are controlled by multiple genes. J. Immunol. 142: 3033 .

Saito, T. and R.N. Germain. 1987. Predictable acquisition of a new MHC recognition specificity following expression of a transfected T-cell receptor beta-chain gene. Nature 329: 256

Samelson, L.E., R.N. Germain, and R.H. Schwartz. 1983. Monoclonal antibodies against the antigen receptor on a cloned T-cell hybrid. Proc. Natl. Acad. Sci. 80: 6972.

Sha, W.C., C.A. Nelson, R.D. Newberry, D.M. Kranz, J.H. Russell, and D.Y. Loh. 1988a. Selective expression of an antigen receptor on CD8-bearing $\mathrm{T}$ lymphocytes in transgenic mice. Nature 335: 271. 
1988b. Positive and negative selection of an antigen receptor on T cells in transgenic mice. Nature 336: 73 .

Singer, A. 1988. Experimentation and thymic selection. $J$. Immunol. 140: 2481.

Singer, A., K.S. Hathcock, and R.J. Hodes. 1981. Self recognition in allogenic radiation bone marrow chimeras. $J$. Exp. Med. 153: 1286.

Sprent, J. 1978. Restricted helper function of $F_{1}$ parent bone marrow chimeras controlled by K-end of $\mathrm{H}-2$ complex. $J$. Exp. Med. 147: 1838.

Sprent, J., D. Lo, E.-K. Gao, and Y. Ron. 1988. T cell selection in the thymus. Immunol. Rev. 101: 173.

Stockinger, H., K. Pfizenmaier, C. Hardt, H. Rodt, M. Rollinghoff, and H. Wagner. 1980 . H-2 restriction as a consequence of intentional priming: $T$ cells of fully allogenic chimeric mice as well as of normal mice respond to foreign alloantigens in the context of $\mathbf{H}-2$ determinants not encountered on thymic epithelial cells. Proc. Natl. Acad. Sci. 77: 7390 .

Takebe, Y., M. Seiki, J. Fujisawa, P. Hoy, K. Yokota, K. Arai, M. Yoshida, and N. Arai. 1988. SR $\alpha$ promoter: An efficient and versatile mammalian cDNA expression system composed of the simian virus 40 early promoter and the R-U5 segment of human T-cell leukemia virus type 1 long terminal repeat. Mol. Cell. Biol. 8: 466.

Traunecker, A., B. Dolder, F. Oliveri, and K. Karjalainen. 1989. Solubilizing the T-cell receptor-Problems in solution. Immunol. Today 10: 29.

van Ewijk, W., R. Ron, J. Monaco, J. Kappler, P. Marrack, M. Le Meur, P. Gerlinger, B. Durand, C. Benoist, and D. Mathis. 1988. Compartmentalization of MHC class II gene expression in transgenic mice. Cell 53: 357.

von Boehmer, H., W. Haas, and N.K. Jerne. 1978. Major histocompatibility complex-linked immune response is acquired by lymphocytes of low responder mice differentiating in thymus of high responder mice. Proc. Natl. Acad. Sci. 75: 2439.

White, J., A. Herman, A.M. Pullen, R. Kubo, J.W. Kappler, and P. Marrack. 1989. The $\mathrm{V}_{\beta}$-specific superantigen staphylococcal enterotoxin B: Stimulation of mature T cells and clonal deletion in neonatal mice. Cell 56: 27.

Zinkernagel, R.M., G.N. Callahan, A. Althage, S. Cooper, P.A. Klein, and J. Klein. 1978. On the thymus in the differentiation of "H-2 self recognition" by T cells: Evidence for dual recognition? J. Exp. Med. 147: 882 . 